\title{
Brain $\beta$-Amyloid and Atrophy in Individuals at Increased Risk of Cognitive Decline
}

\author{
(DI.K. Martikainen, (D) N. Kemppainen, (D). Johansson, (D). Teuho, (D) S. Helin, (D). Liu, DS. Helisalmi, (D) H. Soininen, (D) R. Parkkola, \\ (D)T. Ngandu, (D) M. Kivipelto, and (DJ.O. Rinne
}

\begin{abstract}
BACKGROUND AND PURPOSE: The relationship between brain $\beta$-amyloid and regional atrophy is still incompletely understood in elderly individuals at risk of dementia. Here, we studied the associations between brain $\beta$-amyloid load and regional GM and WM volumes in older adults who were clinically evaluated as being at increased risk of cognitive decline based on cardiovascular risk factors.
\end{abstract}

MATERIALS AND METHODS: Forty subjects (63-81 years of age) were recruited as part of a larger study, the Finnish Geriatric Intervention Study to Prevent Cognitive Impairment and Disability. Neuroimaging consisted of PET using "C Pittsburgh compound-B and T1-weighted 3D MR imaging for the measurement of brain $\beta$-amyloid and GM and WM volumes, respectively. All subjects underwent clinical, genetic, and neuropsychological evaluations for the assessment of cognitive function and the identification of cardiovascular risk factors.

RESULTS: Sixteen subjects were visually evaluated as showing cortical $\beta$-amyloid (positive for $\beta$-amyloid). In the voxel-by-voxel analyses, no significant differences were found in GM and WM volumes between the samples positive and negative for $\beta$-amyloid. However, in the sample positive for $\beta$-amyloid, increases in "C Pittsburgh compound-B uptake were associated with reductions in GM volume in the left prefrontal $(P=.02)$ and right temporal lobes $(P=.04)$.

CONCLUSIONS: Our results show a significant association between increases in brain $\beta$-amyloid and reductions in regional GM volume in individuals at increased risk of cognitive decline. This evidence is consistent with a model in which increases in $\beta$-amyloid incite neurodegeneration in memory systems before cognitive impairment manifests.

ABBREVIATIONS: $\mathrm{AD}=$ Alzheimer disease; $\mathrm{APOE}=$ Apolipoprotein $\mathrm{E} ; \mathrm{A} \beta=\beta$-amyloid; $\mathrm{PIB}=$ Pittsburgh compound $\mathrm{B} ; \mathrm{PIB}-=\mathrm{PIB}$ negative; $\mathrm{PIB}+=\mathrm{PIB}$ positive

A lzheimer disease $(\mathrm{AD})$, the most common form of late-life dementia, is characterized by abnormal deposits of neurofibrillary tangles of $\tau$ protein and plaques of $\beta$-amyloid (A $\beta$ ) protein in the brain, eventually leading to neurodegeneration and cognitive decline. The accumulation of $\mathrm{A} \beta$ in the brain is believed to be a key factor in the development of $\mathrm{AD}$, and recent evidence

Received November 9, 2017; accepted after revision October 12, 2018.

From the Department of Radiology (I.K.M.), Medical Imaging Center, Tampere University Hospital, Tampere, Finland; Division of Clinical Neurosciences (N.K., J.O.R.), Turku University Hospital, Turku, Finland; Turku PET Centre (N.K., J.J., J.T., S. Helin, J.O.R.), University of Turku, Turku, Finland; Department of Neurology (Y.L., S. Helisalmi, H.S., M.K.), University of Eastern Finland, Kuopio, Finland; Neurocenter (Y.L., H.S., M.K.), Neurology, Kuopio University Hospital, Kuopio, Finland; Department of Radiology (R.P.), University of Turku and Turku University Hospital, Turku, Finland; Department of Public Health Solutions (T.N., M.K.), Public Health Promotion Unit, National Institute for Health and Welfare, Helsinki, Finland; and Division of Clinical Geriatrics (T.N., M.K.), Center for Alzheimer Research, Department of Neurobiology, Care Sciences and Society, Karolinska Institutet, Stockholm, Sweden.

This study was supported by Finnish Governmental Research Funding for Turku University Hospital and Tampere University Hospital; the Finnish Medical Foundation; the Sigrid Jusélius Foundation; the Maud Kuistila Foundation; the Paulo Foundation; the Research Council for Health of the Academy of Finland (15762, 259615, 278457, 287490, 294061; and Responding to Public Health Challenges Research Program grants 129395, 129397, 129421, 129416, 129401); the La Carita Foundation; the suggests that reduction of brain $\mathrm{A} \beta$ in the early stages of $\mathrm{AD}$ may slow down cognitive and functional decline. ${ }^{1}$ Therefore, there is a need to find biomarkers that identify individuals at risk of developing $\mathrm{AD}$ pathology who might benefit from therapeutic interventions before substantial irreversible neurodegeneration occurs.

Neuroimaging using PET and ligands specific for $\mathrm{A} \beta$ such as ${ }^{11} \mathrm{C}$-labeled-Pittsburgh compound-B $\left({ }^{11} \mathrm{C} \mathrm{PIB}\right)$ allows the measurement of brain fibrillary $\mathrm{A} \beta$ load in vivo. Previous studies have found increases in brain ${ }^{11} \mathrm{C}$ PIB uptake not only in patients with $\mathrm{AD}$ but also in patients at risk of $\mathrm{AD} .{ }^{2}$ The increases in ${ }^{11} \mathrm{C} \mathrm{PIB}$

\footnotetext{
Alzheimer's Association (grant HAT-10-173121); the Juho Vainio Foundation; the Novo Nordisk Foundation; the Finnish Social Insurance Institution; the Ministry of Education and Culture, Finland; the Swedish Research Council; the Alzheimer's Research and Prevention Foundation, United States; the AXA Research Fund; the Sheikha Salama bint Hamdan Al Nahyan Foundation; the Academy of Finland for Joint Program of Neurodegenerative Disorders-prevention (Multimodal preventive trials for Alzheimer's Disease); the Swedish Research Council; and the Swedish Research Council for Health, Working Life, and Welfare.

Please address correspondence to Ilkka K. Martikainen, MD, Department of Radiology, Medical Imaging Center, Tampere University Hospital, PO Box 2000, 33521 Tampere, Finland; e-mail: ilkka.martikainen@pshp.f; @IKMartikainen

- - Indicates open access to non-subscribers at www.ajnr.org

http://dx.doi.org/10.3174/ajnr.A5891
} 
uptake in these patient samples are significantly associated with brain atrophy. ${ }^{3,4}$ However, the evidence is mixed on the relationship of brain volumes and $\mathrm{A} \beta$ load in elderly subjects without clear cognitive impairment: Earlier studies have found both positive $^{5,6}$ and negative associations ${ }^{7}$ or no associations. ${ }^{8}$ This inconsistency may be related to differences in methodology and the stage of $\mathrm{AD}$ pathology of the samples.

Here, we studied the relationships between brain $\mathrm{A} \beta$ and apolipoprotein $E(A P O E) \varepsilon 4$ carrier status with regional GM and WM volumes in a population-based sample of elderly individuals without manifest cognitive impairment but at high risk of developing dementia based on a cardiovascular risk factor profile. Earlier research suggests substantial regional variation in the accelerated brain atrophy related to early $\mathrm{A} \beta$ accumulation. ${ }^{9}$ Therefore, we hypothesized that increases in ${ }^{11} \mathrm{C}$ PIB uptake are associated with specific patterns of brain volume loss. A better understanding of the relationship between $\mathrm{A} \beta$ and brain atrophy would not only elucidate $\mathrm{AD}$ mechanisms in at-risk subjects but also potentially help develop imaging-based identification of individuals who might benefit from early intervention.

\section{MATERIALS AND METHODS Subjects}

The subjects were recruited as part of the Finnish Geriatric Intervention Study to Prevent Cognitive Impairment and Disability (clinicaltrials.gov identifier NCT01041989). The study enrolled subjects 60-77 years of age with Cardiovascular Risk Factors, Aging and Dementia scores of at least 6 points ${ }^{10}$ and cognition at a mean level or slightly lower than that expected for age. At least 1 of the following criteria was required for inclusion: 1) Word List Memory Task of $\leq 19$ words, 2) Word List Recall of $\leq 75 \%$, or 3 ) Mini-Mental State Examination score of $\leq 26 / 30$ points. In general, the subjects are representative of the Finnish elderly population with several risk factors for dementia. ${ }^{11,12}$ The exclusion criteria included major depression, dementia, or marked cognitive decline, Mini-Mental State Examination scores of $<20$, and symptomatic cardiovascular disease.

Here, we studied a subgroup of the above-mentioned sample (Turku University Hospital cohort), consisting of 40 subjects ( 21 men, 19 women; mean age, $71 \pm 5.2$ years). Before analyses, all neuroimaging data were evaluated for image quality. Written informed consent was obtained from all subjects who participated in the study. The study was approved by the Coordinating Ethics Committee of the Helsinki and Uusimaa Hospital District.

\section{Clinical Measurements}

The clinical measurements have been previously described in detail. ${ }^{13}$ The cognitive performance was evaluated using the modified Neuropsychological Test Battery, ${ }^{14}$ yielding a total composite $z$ score and domain $z$ score measures of memory, executive function, and processing speed. Total serum cholesterol and plasma glucose concentrations were determined enzymatically using commercial reagents and a clinical chemistry analyzer, Architect c8000 (Abbott Laboratories, Abbott Park, Illinois).

\section{APOE Genotyping}

Genomic DNA was extracted from venous blood samples with a chemagic Magnetic Separation Module I (Perkin Elmer, Waltham, Massachusetts) using magnetic beads. The APOE genotype was determined by polymerase chain reaction using TaqMan genotyping assays (Applied Biosystems, Foster City, California) for 2 single-nucleotide polymorphisms (rs429358 and rs7412) and an allelic discrimination method on the ABI 7500 platform (Applied Biosystems). ${ }^{15}$

\section{Neuroimaging}

${ }^{11} \mathrm{C}$ PIB [N-methyl- ${ }^{11} \mathrm{C}-2$-(4-methylaminophenyl)-6-hydroxybenzothiazole] was produced as described earlier. ${ }^{16}$ On average, $406 \pm 110 \mathrm{MBq}$ of ${ }^{11} \mathrm{C} \mathrm{PIB}$ was injected intravenously, and a scan from 60 to 90 minutes $(3 \times 10$-minute frames $)$ after injection was performed with an Ingenuity TF PET/MR scanner (Philips Healthcare, Best, the Netherlands). All images were reconstructed using a line-of-response row-action maximum likelihood algorithm with MR imaging-based attenuation correction using a segmentation-based algorithm with 3 tissue classes, including the head coil template used in the MR imaging protocol. ${ }^{17}$ The data were reconstructed using 2 iterations and 33 subsets. The image matrix size was $128 \times 128 \times 90$, with an axial FOV of $256 \times 256$ $\mathrm{mm}$ and an isotropic voxel dimension of $2 \mathrm{~mm}$. All quantitative corrections for PET data were applied, including scatter, randoms, attenuation, detector deadtime, and normalization. Neither time-of-flight information nor resolution modeling was applied in this study. Sagittal T1-weighted 3D MR imaging data were acquired for the measurement of brain GM and WM volumes, with $\mathrm{TR}=25 \mathrm{~ms}, \mathrm{TE}=5.5 \mathrm{~ms}$, and a reconstructed isotropic voxel dimension of $1 \mathrm{~mm}$.

\section{PET and MR Imaging Data Processing}

The neuroimaging data were processed using SPM8 (http://www. fil.ion.ucl.ac.uk/spm/software/spm12). The ${ }^{11} \mathrm{C}$ PIB images were realigned and coregistered to the individual MR image and normalized to Montreal Neurological Institute space. ${ }^{11} \mathrm{C}$ PIB uptake data were extracted using the standard automated segmentations by FreeSurfer 5.0 (http://surfer.nmr.mgh.harvard.edu). ${ }^{18}$ Regional ${ }^{11} \mathrm{C}$ PIB uptake was quantified as a region-to-cerebellar cortex ratio during the 60 - to 90 -minute scan duration. The ${ }^{11} \mathrm{C}$ PIB uptake values in the right and left hemispheres were averaged for data analysis.

MR imaging data processing for voxel-based morphometry analysis was performed using the VBM8 toolbox (http://dbm. neuro.uni-jena.de/vbm.html), with default parameters for image processing. This included bias regularization and tissue classification and registration using linear (affine) and nonlinear transformations within a unified model. ${ }^{19}$ High-dimensional spatial normalization was accomplished using Diffeomorphic Anatomical Registration Through Exponentiated Lie Algebra. The analysis was performed on the volumes of GM and WM, multiplied by the nonlinear, but not linear, components derived from the normalization matrix. This procedure preserves actual local GM and WM volumes, accounting for individual brain size (modulated volume). The realigned and normalized GM and WM segments 
Table 1: Sample demographics and clinical characteristics ${ }^{a}$

\begin{tabular}{|c|c|c|c|c|}
\hline Characteristics & All & PIB- & $\mathrm{PIB}+$ & PIB- vs PIB+ \\
\hline No. (\% women) & $40(48 \%)$ & $24(50 \%)$ & $16(44 \%)$ & $\chi_{1}^{2}=0.15, P=.70$ \\
\hline Age (yr) & $71 \pm 5$ & $70 \pm 6$ & $72 \pm 4$ & $t_{38}=-1.19, P=.24$ \\
\hline APOE $\in 4$ carriers (\%) & $12(31)$ & $4(17)$ & $8(53)$ & $\chi_{1}^{2}=5.83, P=.02$ \\
\hline Body mass index $\left(\mathrm{kg} / \mathrm{m}^{2}\right)$ & $27 \pm 3$ & $28 \pm 3$ & $26 \pm 2$ & $t_{38}=2.14, P=.04$ \\
\hline Systolic blood pressure (mm Hg) & $137 \pm 15$ & $138 \pm 15$ & $136 \pm 15$ & $\mathrm{t}_{38}=0.31, P=.76$ \\
\hline Diastolic blood pressure (mm Hg) & $81 \pm 8$ & $80 \pm 8$ & $82 \pm 9$ & $\mathrm{t}_{38}=-0.65, P=.52$ \\
\hline Total serum cholesterol level (mmol/L) & $5.2 \pm 1$ & $4.9 \pm 1$ & $5.5 \pm 1$ & $\mathrm{t}_{38}=1.69, P=.10$ \\
\hline Education (yr) & $9(2)$ & $9(2.75)$ & $8(2)$ & $\mathrm{U}=158, P=.36$ \\
\hline Physical activity $\geq$ twice per week (\%) & 63 & 52 & 80 & $\chi_{1}^{2}=3.02, P=.08$ \\
\hline Mini-Mental State Examination & $27(2)$ & $27(2)$ & $27(3)$ & $\mathrm{U}=158, P=.35$ \\
\hline Total composite $z$ score & $0.03 \pm 0.5$ & $0.06 \pm 0.6$ & $-0.01 \pm 0.5$ & $F_{1,37}=0.018, P=.90$ \\
\hline Memory z score & $-0.05 \pm 0.6$ & $-0.10 \pm 0.5$ & $0.06 \pm 0.7$ & $F_{1,37}=2.42, P=.13$ \\
\hline Executive function $z$ score & $0.04 \pm 0.6$ & $0.20 \pm 0.6$ & $-0.10 \pm 0.4$ & $F_{1,37}=1.94, P=.17$ \\
\hline Processing speed $z$ score & $0.2(0.9)$ & $0.4(1)$ & $0.2(1)$ & $F_{1,37}=0.03, P=.86$ \\
\hline Dementia risk score & $7.5(3.75)$ & $8(3.75)$ & $7(2)$ & $\mathrm{U}=161, P=.39$ \\
\hline Fazekas score & $1(2)$ & $1(2)$ & $2(1.75)$ & $U=144, P=.18$ \\
\hline
\end{tabular}

${ }^{a}$ Data are given as mean \pm SD or median (interquartile range).

were smoothed with a Gaussian kernel with a full width at half maximum size of $8 \mathrm{~mm}$.

\section{Data Analysis}

The PET images were visually interpreted by 2 experienced readers, and subjects were classified as either PIB positive $(\mathrm{PIB}+)$ or $\mathrm{PIB}$ negative $(\mathrm{PIB}-)$ on the basis of consensus agreement. The subjects with $\mathrm{PIB}+$ findings had cortical ${ }^{11} \mathrm{C} \mathrm{PIB}$ retention in at least 1 region typically affected by $\beta$-amyloid deposition in $\mathrm{AD}$, while the subjects with $\mathrm{PIB}$ - findings had only nonspecific ${ }^{11} \mathrm{C}$ PIB retention in the WM. Brain GM and WM volumes were compared between the PIB + and PIB - samples and APOE $\varepsilon 4$ carriers and noncarriers voxel-by-voxel using an unpaired $t$ test. The associations between ${ }^{11} \mathrm{C}$ PIB uptake and brain GM and WM volumes, and interactions between ${ }^{11} \mathrm{C} \mathrm{PIB}$ uptake and $A P O E \varepsilon 4$ carrier status with regional GM and WM volumes were analyzed using whole-brain voxel-by-voxel multiple linear regression analysis. Age and sex were covaried in all analyses. Primary analyses were conducted using a composite ${ }^{11} \mathrm{C}$ PIB uptake value, calculated as the average uptake in the following regions: anterior cingulate cortex, lateral temporal cortex, parietal cortex, posterior cingulate cortex, precuneus, and prefrontal cortex. Additionally, the ${ }^{11} \mathrm{C}$ PIB uptake values for the precuneus, prefrontal cortex, and posterior cingulate cortex were used for regression analysis because they are among the first regions to show increases in ${ }^{11} \mathrm{C}$ PIB uptake in mild cognitive impairment. ${ }^{2}$ The associations were determined separately in the PIB + and PIB - samples.

Voxels with GM or WM values of $<0.1$ were excluded from the analysis. A height threshold of $P<.001$ (uncorrected) was used across the whole brain for searching significant differences in brain GM and WM volumes $(P<.05$, family-wise error ratecorrected for multiple comparisons at the cluster level). Extent threshold was defined by the expected number of voxels per cluster based on random field theory. Cluster sizes were adjusted for nonstationary smoothness. ${ }^{20}$ In addition to the measures of GM and WM volume, microangiopathy-related hyperintensities in deep WM were evaluated on axial FLAIR images using a semiquantitative scale $(0=$ absence, $1=$ punctate foci, $2=$ beginning confluence of foci, 3 = large confluent areas). ${ }^{21}$

Statistical analyses were performed using SPSS, Version 23.0
(SPSS Statistics for Windows; IBM, Armonk, New York). Planned correlations were determined between clinical measures and GM and WM volumes in the PIB + and PIB - samples. In these analyses, statistical significance was set at $P<.05$, and no correction for multiple tests was applied to these correlations.

\section{RESULTS \\ General Characteristics and APOE Genotype of the Subjects}

The general characteristics of the subjects are shown in Table 1. APOE genotype was determined in 39 subjects. This sample consisted of 12 APOE $\varepsilon 4$ carriers $(\varepsilon 2 / \varepsilon 4, n=1 ; \varepsilon 3 / \varepsilon 4, n=10 ; \varepsilon 4 / \varepsilon 4$, $n=1)$ and 27 APOE $\varepsilon 4$ noncarriers $(\varepsilon 2 / \varepsilon 3, n=2 ; \varepsilon 3 / \varepsilon 3, n=25)$.

\section{Brain " C PIB Uptake and GM and WM Volumes}

The average global brain GM volume was $618 \pm 73 \mathrm{~mL}$ in the $\mathrm{PIB}+$ sample and $624 \pm 52 \mathrm{~mL}$ in the $\mathrm{PIB}-$ sample, and the average brain WM volume was $502 \pm 76 \mathrm{~mL}$ in the $\mathrm{PIB}+$ sample and $520 \pm 61 \mathrm{~mL}$ in the PIB - sample. There were no differences in the global GM and WM volumes between the samples (GM: $F_{1,37}=0.17, P=.68$; WM: $F_{1,37}=1.21, P=.28$ ). In the wholebrain voxel-by-voxel analyses, no significant differences were found in the GM and WM volumes between the PIB + and PIBsamples, even when using a very lenient search threshold $(P<.05$, uncorrected).

In line with our earlier work, significant correlations were found between the regional ${ }^{11} \mathrm{C}$ PIB uptake values and the composite ${ }^{11} \mathrm{C}$ PIB uptake value in the $\mathrm{PIB}+$ sample (all bivariate ROI correlations, $P \leq .001$; Pearson $r=0.70-0.98)$. Therefore, the composite ${ }^{11} \mathrm{C}$ PIB uptake value can be used as a proxy for overall brain $A \beta$ load in this study.

In the $\mathrm{PIB}+$ sample, increases in composite ${ }^{11} \mathrm{C}$ PIB uptake were associated with smaller GM volumes in the right temporal lobe (temporal pole, parahippocampal gyrus; peak Montreal Neurological Institute coordinates at $[29,14,-30]$, cluster size $=$ $\left.1170 \mathrm{~mm}^{3}, z=4.0, P=.04\right)$. At a lower search threshold $(P<$ .01 ), this region also encompassed the right hippocampus and areas of the medial occipitotemporal gyrus (Fig $A,-B$ ). The increases in ${ }^{11} \mathrm{C}$ PIB uptake in the precuneus were associated with smaller GM volumes in the left prefrontal lobe (inferior frontal 
gyrus; $[-38,32,4], 262 \mathrm{~mm}^{3}, z=3.8, P=.02$; Fig $\left.C\right)$. At trend level $(P=.06)$, an association was found between increases in ${ }^{11} \mathrm{C}$ PIB uptake in the prefrontal cortex and smaller GM volumes in the right temporal lobe (temporal pole, parahippocampal gyrus, amygdala; $[29,12,-30], 1390 \mathrm{~mm}^{3}, z=3.7$ ). There were no regions with a significant positive correlation between ${ }^{11} \mathrm{C}$ PIB uptake and GM volume. In the PIB - sample, no significant associations were found between brain ${ }^{11} \mathrm{C}$ PIB uptake and GM volume (all regions, $P>.05$ ). No significant associations were found between ${ }^{11} \mathrm{C}$ PIB uptake and regional WM volume in the PIB + or PIB - samples. The main results are summarized in Table 2.

\section{APOE $\varepsilon 4$ Carrier Status and GM and WM Volumes}

No significant differences were found in global brain GM volumes between $A P O E \varepsilon 4$ carriers and noncarriers $\left(F_{1,36}=1.44, P=.24\right)$. The global WM volumes were significantly smaller in APOE $\varepsilon 4$ carriers compared with noncarriers $\left(F_{1,36}=4.62, P=.04\right)$. In the whole-brain voxel-by-voxel analysis, no significant differences were found in regional GM volumes when comparing APOE $\varepsilon 4$ carriers and noncarriers. Furthermore, no significant interactions
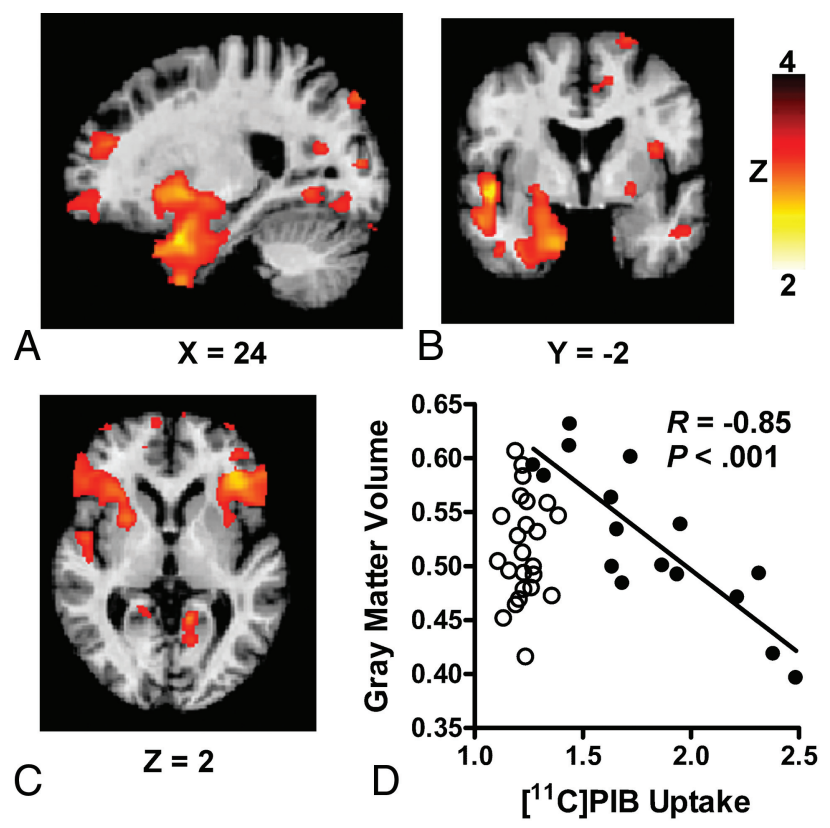

FIGURE. Associations between increases in ${ }^{11} \mathrm{C}$ PIB uptake and reductions in GM volume in subjects with PIB + findings at increased risk of cognitive decline. In subjects classified as positive for " $\mathrm{C}$ PIB uptake, significant associations are found between increases in composite " $\mathrm{C}$ PIB uptake and reductions in GM volume in the right temporal lobe ( $A$ and $B)$ and increases in ${ }^{11} C \mathrm{PIB}$ uptake in the precuneus and reductions in GM volume in the left prefrontal lobe $(C)$. $D$, The significant negative correlation between composite ${ }^{11} \mathrm{CPIB}$ uptake and GM volume in the right temporal lobe in the PIB + sample (closed circles). No correlation is found in the PIB - sample (open circles). The $R$ and $P$ values were calculated using the average $\mathrm{GM}$ volumes extracted at $P<.001$. were found between $A P O E \varepsilon 4$ carrier status and composite ${ }^{11} \mathrm{C}$ PIB uptake with regional GM volume. Regarding regional WM, $A P O E \varepsilon 4$ carriers had significant reductions in WM volumes in the right parieto-occipital region compared with $A P O E \varepsilon 4$ noncarriers $\left([18,-87,32], 4810 \mathrm{~mm}^{3}, z=4.7, P=.001\right)$. No significant regions were found in the opposite contrast (APOE $\varepsilon 4$ carriers $>A P O E \& 4$ noncarriers). No interactions were found between $A P O E \varepsilon 4$ carrier status and composite ${ }^{11} \mathrm{C}$ PIB uptake with regional WM volume.

\section{Clinical Correlations}

In the overall sample, larger global GM and WM volumes were associated with younger age (GM: $r=-0.35, P=.01$; WM: $r=$ $-0.37, P=.009)$. Larger global WM volumes were also associated with higher Mini-Mental State Examination scores at trend level $(r=0.28, P=.08)$. Correlations between regional GM or WM volumes and clinical measures, including WM hyperintensities, were short of significance (all $P$ values $>.05$ ).

\section{DISCUSSION}

PET imaging using ligands specific for $\mathrm{A} \beta$, such as ${ }^{11} \mathrm{C}$ PIB, allows the evaluation of $\mathrm{AD}$ pathology even before clinical symptoms emerge. However, a number of patients with PET scans positive for ${ }^{11} \mathrm{C}$ PIB do not develop $\mathrm{AD}$, indicating that other biomarkers are needed to accurately identify individuals who might benefit from pharmaceutical or life-style interventions. ${ }^{1,12}$ Earlier studies in patients with $\mathrm{AD}$ and its prodromal states have found significant correlations between ${ }^{11} \mathrm{C}$ PIB uptake and brain volume loss, ${ }^{3,4,22,23}$ which is more closely related to the cognitive symptoms than $\mathrm{A} \beta$ load. ${ }^{6,8}$ Significant correlations have been described between brain $\mathrm{A} \beta$ accumulation and atrophy even in elderly subjects with no cognitive symptoms ${ }^{5,6}$; in fact, it has been suggested that this correlation is particularly strong at early stages of $\mathrm{AD}$ pathology. ${ }^{24,25}$ Our present data extend the previous observations by showing significant associations between increases in brain $\mathrm{A} \beta$ and GM loss in elderly subjects at high risk of cognitive impairment. However, some studies in cognitively healthy subjects have failed to find associations between ${ }^{11} \mathrm{C}$ PIB uptake and atrophy ${ }^{8}$ or have even suggested a positive correlation between ${ }^{11} \mathrm{C}$ PIB uptake and GM volume. ${ }^{7}$ Considering the distinct time scales of brain $\mathrm{A} \beta$ accumulation and GM loss, these discrepancies may relate to differences in the stage of $\mathrm{AD}$ pathology among the samples.

In the PIB + sample, a significant association was found between increases in the composite measure of brain ${ }^{11} \mathrm{C}$ PIB uptake and smaller GM volumes in the right temporal lobe, encompassing structures of the medial temporal lobe memory system. This finding is in line with previous work in cognitively healthy elderly subjects $^{5,6,24,25}$ and suggests that asymptomatic elderly individuals who are at risk of cognitive decline and have a substantial brain $\mathrm{A} \beta$ load show signs of impending neurodegeneration in

\section{Table 2: Summary of associations between "C PIB uptake and brain regional GM volume}

\begin{tabular}{ll}
\hline${ }^{1}$ C PIB Uptake Measure & \multicolumn{1}{c}{$\begin{array}{c}\text { Correlation with GM Volume; Region; Peak X, Y, Z } \\
\text { Coordinates; Cluster Size; } z \text { Score; } P \text { Value }\end{array}$} \\
\hline Composite & Negative correlation, right temporal lobe $(29,14,-30), 1170 \mathrm{~mm}^{3}, z=4.0, P=.04$ \\
Precuneus & Negative correlation, left prefrontal lobe $(-38,32,4), 262 \mathrm{~mm}^{3}, z=3.8, P=.02$ \\
Prefrontal cortex & Negative correlation, right temporal lobe $(29,12,-30), 1390 \mathrm{~mm}^{3}, z=3.7, P=.06$ \\
\hline
\end{tabular}


the temporal lobe. Although no significant associations were found between temporal lobe volume and cognition (MiniMental State Examination, total $z$ score, and subscores of the modified Neuropsychological Test Battery), the significance of coexisting brain $A \beta$ load and temporal lobe atrophy in clinically healthy elderly is highlighted by data suggesting that the adverse effect of these variables on cognition is synergistic. ${ }^{26}$ Therefore, it is likely that the subjects with PIB + findings with temporal lobe atrophy in this study are at high risk of future cognitive decline.

In addition, increases in ${ }^{11} \mathrm{C}$ PIB uptake in the precuneus in the PIB+ sample were significantly associated with GM volume reductions in the left prefrontal lobe. While studies on brain atrophy in the context of $\mathrm{AD}$ pathology have generally focused on medial temporal lobe structures, $\mathrm{AD}$ has also been shown to be associated with atrophy in a number of other brain regions, including the frontal lobes, precuneus, and posterior cingulate cortex. ${ }^{27,28}$ Furthermore, brain $\mathrm{A} \beta$ load in cognitively healthy elderly has been shown to be associated with GM volume loss in the frontal, parietal, and temporal lobes. ${ }^{5,27}$ There is even evidence suggesting that emerging $\mathrm{A} \beta$ pathology in cognitively healthy elderly is particularly associated with frontoparietal atrophy, while atrophy in the temporal lobe structures accelerates later as clinical symptoms begin to manifest. ${ }^{29}$ The mechanisms behind the regional differences in $\mathrm{A} \beta$-associated atrophy are not well-understood: Potential mechanisms include differences in the afferent and efferent connections and vulnerability to $\mathrm{A} \beta$ related toxicity.

Earlier studies have shown that the APOE $\varepsilon 4$ allele is associated with CSF $A \beta$ levels and changes in brain GM and WM in mild cognitive impairment and $\mathrm{AD} .^{30-32}$ Although regional reductions in WM volumes were found in APOE $\varepsilon 4$ carriers compared with noncarriers, the $A P O E \varepsilon 4$ carrier status had no effect on the relationship between ${ }^{11} \mathrm{C}$ PIB uptake and GM volume, corroborating the results from previous studies conducted in clinically healthy elderly and subjects with mild cognitive impairment. ${ }^{33,34}$ These findings are in line with evidence showing that while APOE $\varepsilon 4$ carrier status has a major effect on $\mathrm{A} \beta$ deposition, the effects on atrophy are subtle and are mediated by both $\mathrm{A} \beta$-dependent and $\mathrm{A} \beta$-independent mechanisms. ${ }^{35}$

Finally, this study has a few limitations. First, because the subjects were clinically selected to represent an elderly population with several risk factors for dementia, it is likely that they have mixed pathologies; conversely, some of the pathologies related to cognitive impairment may not have been considered in the current study. Second, the sample size was relatively small for the evaluation of associations between GM and WM volumes and clinical variables and the effects of $A P O E \varepsilon 4$ on the relationship between ${ }^{11} \mathrm{C}$ PIB uptake and GM and WM volumes. Third, the cross-sectional data do not allow determining whether the subjects with PIB + findings with impending temporal lobe atrophy develop cognitive impairment later on. Therefore, replication of these findings in larger samples as well as longitudinal studies are needed to determine the predictive power of ${ }^{11} \mathrm{C}$ PIB PET and GM volume in cognitive impairment in at-risk elderly individuals.

\section{CONCLUSIONS}

Our results show that elderly individuals who are at increased risk of cognitive decline based on cardiovascular risk factors and have PET scans positive for ${ }^{11} \mathrm{C}$ PIB exhibit reductions in regional GM volume in proportion to increases in brain $A \beta$ load. Our findings are consistent with the model in which brain $\mathrm{A} \beta$ accumulation incites neurodegeneration before cognitive decline manifests. Furthermore, the results suggest that the brain $A \beta$-associated GM loss affects both the medial temporal lobe memory system and the neocortex. Together this evidence emphasizes the importance of finding biomarkers that identify individuals at risk of developing AD pathology who might still benefit from therapeutic interventions.

\section{ACKNOWLEDGMENTS}

The assistance of the personnel of the Turku PET Centre in acquiring PET and MR imaging data is gratefully acknowledged.

Disclosures: Ilkka Martikainen—RELATED: Grant: Finnish Governmental Research Funding for Tampere University Hospital.* Nina Kemppainen-RELATED: Grant: Turku University Hospital, the Finnish Medical Foundation, the Sigrid Jusélius Foundation, the Maud Kuistila Foundation, the Paulo Foundation; UNRELATED: Employment: Turku University Hospital. Hilkka Soininen—RELATED: Grant: Academy of Finland*; UNRELATED: Board Membership: AC Immune; Consultancy: Merck. Tiia Ngandu—RELATED: Grant: Finnish Medical Foundation. * Miia Kivipelto-UNRELATED: Payment for Lectures Including Service on Speakers Bureaus: Nestlé. Juha O. RinneRELATED: Grant: Sigrid Jusélius Foundation, Comments: unrestricted academic grant*; UNRELATED: Consultancy: Clinical Research Services Turku Ltd, Comments: fee for serving as a consultant neurologist. *Money paid to the institution.

\section{REFERENCES}

1. Sevigny J, Chiao $\mathrm{P}$, Bussière $\mathrm{T}$, et al. The antibody aducanumab reduces A $\boldsymbol{\beta}$ plaques in Alzheimer's disease. Nature 2016;537:50-56 CrossRef Medline

2. Kemppainen NM, Aalto S, Wilson IA, et al. PET amyloid ligand [11C] PIB uptake is increased in mild cognitive impairment. Neurology 2007;68:1603-06 CrossRef Medline

3. Archer HA, Edison P, Brooks DJ, et al. Amyloid load and cerebral atrophy in Alzheimer's disease: an 11C-PIB positron emission tomography study. Ann Neurol 2006;60:145-47 CrossRef Medline

4. Tosun D, Schuff N, Mathis CA, et al; Alzheimer's Disease Neuroimaging Initiative. Spatial patterns of brain amyloid-beta burden and atrophy rate associations in mild cognitive impairment. Brain 2011; 134:1077-88 CrossRef Medline

5. Oh H, Madison C, Villeneuve S, et al. Association of gray matter atrophy with age, $\boldsymbol{\beta}$-amyloid, and cognition in aging. Cereb Cortex 2014;24:1609-18 CrossRef Medline

6. Storandt M, Mintun MA, Head D, et al. Cognitive decline and brain volume loss as signatures of cerebral amyloid-beta peptide deposition identified with Pittsburgh compound B: cognitive decline associated with Abeta deposition. Arch Neurol 2009;66:1476-81 Medline

7. Chételat G, Villemagne VL, Pike KE, et al; Australian Imaging Biomarkers and Lifestyle Study of Ageing (AIBL) Research Group. Larger temporal volume in elderly with high versus low beta-amyloid deposition. Brain 2010;133:3349-58 CrossRef Medline

8. Jack CR Jr, Lowe VJ, Weigand SD, et al; Alzheimer's Disease Neuroimaging Initiative. Serial PIB and MRI in normal, mild cognitive impairment and Alzheimer's disease: implications for sequence of pathological events in Alzheimer's disease. Brain 2009;132:1355-65 CrossRef Medline

9. Insel PS, Mattsson N, Donohue MC, et al. The transitional association between $\boldsymbol{\beta}$-amyloid pathology and regional brain atrophy. Alzheimers Dement 2015;11:1171-79 CrossRef Medline

10. Kivipelto M, Ngandu T, Laatikainen T, et al. Risk score for the pre- 
diction of dementia risk in 20 years among middle aged people: a longitudinal, population-based study. Lancet Neurol 2006;5:735-41 CrossRef Medline

11. Kivipelto M, Solomon A, Ahtiluoto S, et al. The Finnish Geriatric Intervention Study to Prevent Cognitive Impairment and Disability (FINGER): study design and progress. Alzheimers Dement 2013; 9:657-65 CrossRef Medline

12. Ngandu T, Lehtisalo J, Solomon A, et al. A 2 year multidomain intervention of diet, exercise, cognitive training, and vascular risk monitoring versus control to prevent cognitive decline in at-risk elderly people (FINGER): a randomised controlled trial. Lancet 2015;385:2255-63 CrossRef Medline

13. Ngandu T, Lehtisalo J, Levälahti E, et al. Recruitment and baseline characteristics of participants in the Finnish Geriatric Intervention Study to Prevent Cognitive Impairment and Disability (FINGER)-a randomized controlled lifestyle trial. Int J Environ Res Public Health 2014;11:9345-60 CrossRef Medline

14. Harrison J, Minassian SL, Jenkins L, et al. A neuropsychological test battery for use in Alzheimer disease clinical trials. Arch Neurol 2007; 64:1323-29 CrossRef Medline

15. De la Vega FM, Lazaruk KD, Rhodes MD, et al. Assessment of two flexible and compatible SNP genotyping platforms: TaqMan SNP Genotyping Assays and the SNPlex Genotyping System. Mutat Res 2005;573:111-35 CrossRef Medline

16. Snellman A, Rokka J, López-Picón FR, et al. Applicability of [(11)C]PIB micro-PET imaging for in vivo follow-up of anti-amyloid treatment effects in APP23 mouse model. Neurobiol Aging 2017; 57:84-94 CrossRef Medline

17. Schulz V, Torres-Espallardo I, Renisch S, et al. Automatic, three-segment, MR-based attenuation correction for whole-body PET/MR data. Eur J Nucl Med Mol Imaging 2011;38:138-52 CrossRef Medline

18. Fischl B, Salat DH, Busa E, et al. Whole brain segmentation: automated labeling of neuroanatomical structures in the human brain. Neuron 2002;33:341-55 CrossRef Medline

19. Ashburner J, Friston KJ. Unified segmentation. Neuroimage 2005;26: 839-51 CrossRef Medline

20. Hayasaka S, Phan KL, Liberzon I, et al. Nonstationary cluster-size inference with random field and permutation methods. Neuroimage 2004;22:676-87 CrossRef Medline

21. Fazekas F, Chawluk JB, Alavi A, et al. MR signal abnormalities at $\mathbf{1 . 5}$ $\mathrm{T}$ in Alzheimer's dementia and normal aging. AJR Am J Roentgenol 1987;149:351-56 CrossRef Medline

22. Jack CR Jr, Lowe VJ, Senjem ML, et al. 11C PiB and structural MRI provide complementary information in imaging of Alzheimer's disease and amnestic mild cognitive impairment. Brain 2008;131: 665-80 CrossRef Medline

23. Mormino EC, Kluth JT, Madison CM, et al; Alzheimer's Disease Neu- roimaging Initiative. Episodic memory loss is related to hippocampal-mediated beta-amyloid deposition in elderly subjects. Brain 2009;132:1310-23 CrossRef Medline

24. Bourgeat P, Chételat G, Villemagne VL, et al; AIBL Research Group. Beta-amyloid burden in the temporal neocortex is related to hippocampal atrophy in elderly subjects without dementia. Neurology 2010;74:121-27 CrossRef Medline

25. Chételat G, Villemagne VL, Bourgeat P, et al; Australian Imaging Biomarkers and Lifestyle Research Group. Relationship between atrophy and beta-amyloid deposition in Alzheimer disease. Ann Neurol 2010;67:317-24 CrossRef Medline

26. Mormino EC, Betensky RA, Hedden T, et al. Synergistic effect of $\boldsymbol{\beta}$-amyloid and neurodegeneration on cognitive decline in clinically normal individuals. JAMA Neurol 2014;71:1379-85 CrossRef Medline

27. Dickerson BC, Bakkour A, Salat DH, et al. The cortical signature of Alzheimer's disease: regionally specific cortical thinning relates to symptom severity in very mild to mild $\mathrm{AD}$ dementia and is detectable in asymptomatic amyloid-positive individuals. Cereb Cortex 2009;19:497-510 CrossRef Medline

28. Lerch JP, Pruessner JC, Zijdenbos A, et al. Focal decline of cortical thickness in Alzheimer's disease identified by computational neuroanatomy. Cereb Cortex 2005;15:995-1001 CrossRef Medline

29. Mattsson N, Insel PS, Nosheny R, et al. Emerging $\boldsymbol{\beta}$-amyloid pathology and accelerated cortical atrophy. JAMA Neurol 2014;71:725-34 CrossRef Medline

30. Galasko D, Chang L, Motter R, et al. High cerebrospinal fluid tau and low amyloid beta42 levels in the clinical diagnosis of Alzheimer disease and relation to apolipoprotein E genotype. Arch Neurol 1998; 55:937-45 CrossRef Medline

31. Honea RA, Vidoni E, Harsha A, et al. Impact of APOE on the healthy aging brain: a voxel-based MRI and DTI study. J Alzheimers Dis 2009;18:553-64 CrossRef Medline

32. Liu Y, Paajanen T, Westman E, et al; AddNeuroMed Consortium. Effect of APOE $\varepsilon 4$ allele on cortical thicknesses and volumes: the AddNeuroMed study. J Alzheimers Dis 2010;21:947-66 CrossRef Medline

33. Becker JA, Hedden T, Carmasin J, et al. Amyloid- $\boldsymbol{\beta}$ associated cortical thinning in clinically normal elderly. Ann Neurol 2011;69: 1032-42 CrossRef Medline

34. Falahati F, Ferreira D, Muehlboeck JS, et al. Monitoring disease progression in mild cognitive impairment: associations between atrophy patterns, cognition, APOE and amyloid. Neuroimage Clin 2017; 16:418-28 CrossRef Medline

35. Chételat G, Fouquet M. Neuroimaging biomarkers for Alzheimer's disease in asymptomatic APOE4 carriers. Rev Neurol (Paris) 2013; 169:729-36 CrossRef Medline 